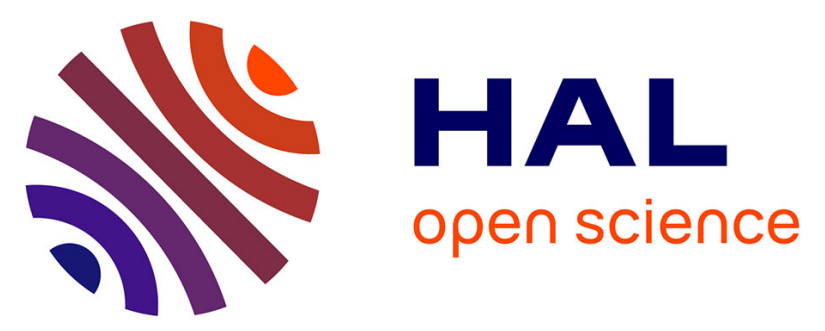

\title{
Propagation analysis of plasmaspheric hiss using Polar PWI measurements
}

\author{
O. Santolík, Michel Parrot, L. R O Storey, J. Pickett, D. A Gurnett
}

\section{To cite this version:}

O. Santolík, Michel Parrot, L. R O Storey, J. Pickett, D. A Gurnett. Propagation analysis of plasmaspheric hiss using Polar PWI measurements. Geophysical Research Letters, 2001, 28 (6), pp.1127-1130. 10.1029/2000GL012239 . insu-03039716

\section{HAL Id: insu-03039716 https://hal-insu.archives-ouvertes.fr/insu-03039716}

Submitted on 4 Dec 2020

HAL is a multi-disciplinary open access archive for the deposit and dissemination of scientific research documents, whether they are published or not. The documents may come from teaching and research institutions in France or abroad, or from public or private research centers.
L'archive ouverte pluridisciplinaire HAL, est destinée au dépôt et à la diffusion de documents scientifiques de niveau recherche, publiés ou non, émanant des établissements d'enseignement et de recherche français ou étrangers, des laboratoires publics ou privés. 


\title{
Propagation analysis of plasmaspheric hiss using Polar PWI measurements
}

\author{
O. Santolík, ${ }^{1,2}$ M. Parrot, ${ }^{1}$ L. R. O. Storey, ${ }^{3}$ J. S. Pickett, ${ }^{4}$ and D. A. Gurnett ${ }^{4}$
}

\begin{abstract}
We have analyzed high-rate waveform data, taken by the POLAR Plasma Wave Instrument at high altitudes in the equatorial plasmasphere, to study plasmaspheric hiss in the range of frequencies between $100 \mathrm{~Hz}$ and several $\mathrm{kHz}$. These emissions are found almost everywhere in the plasmasphere, and their origin is still controversial. Our analysis of several cases shows that most of the waves were propagating more or less parallel to the Earth's magnetic field, but sometimes a few of them were propagating obliquely with their normals near the Gendrin angle. Evidence of amplification was found near the geomagnetic equator. The results suggest that waves with normals both parallel and anti-parallel to the magnetic field were being amplified by the classical mechanism that involves gyroresonant interaction with energetic electrons.
\end{abstract}

\section{Introduction}

Plasmaspheric hiss consists of intense electromagnetic waves in the frequency range between $100 \mathrm{~Hz}$ and several $\mathrm{kHz}$. Satellite observations at altitudes of several Earth radii in the plasmasphere revealed that these natural emissions are almost always present [Thorne et al., 1973]. It is widely thought that the hiss waves get their energy from gyroresonant interaction with the electrons of the inner radiation belt near the plane of the magnetic equator [Kennel and Petschek, 1966]. This amplification process acts best for waves with their normals parallel to the ambient magnetic field $\left(\boldsymbol{B}_{0}\right)$. High amplification rates have been reported on occasions [Solomon et al., 1988], but with the commonly observed electron distribution functions the hiss waves are expected to be amplified by only a few $\mathrm{dB}$ on crossing the equatorial plane. Hence Thorne et al. [1979] suggested that, beginning from background thermal noise, the waves reach the observed intensities by crossing the amplification region many times. This theory supposes that the waves travel on paths that bring them repeatedly back to the equator with their normals close to the magnetic field direction. Thorne et al. [1979] and, more recently, Abel and Thorne [1998] have shown that this can happen if, at some points along their paths, the hiss waves are reflected from the plasmapause.

\footnotetext{
${ }^{1}$ LPCE/CNRS, Orléans, France.

${ }^{2}$ Charles University, Prague, Czech Republic.

${ }^{3}$ Quartier Luchène, Cucuron, France.

${ }^{4}$ Department of Physics and Astronomy, University of Iowa, Iowa City.
}

Copyright 2001 by the American Geophysical Union.

Paper number 2000GL012239.

0094-8276/01/2000GL012239\$05.00
Storey et al. [1991] however observed hiss emissions even when, after long periods of magnetic calm, the plasmapause was absent. They also found that the waves often propagate at large angles from $\boldsymbol{B}_{\mathbf{0}}$, even in the equatorial region. This means these waves cannot be generated exactly in the way Kennel and Petschek [1966] suggested. These results do not directly contradict the theory of Thorne et al. [1973, 1979], but they do suggest that under certain circumstances some other mechanism may be acting. Indeed, highly oblique wave propagation fits a theory developed by Draganov et al. [1992], though due initially to H. C. Koons; see page 19,486 of Storey et al. [1991]. On this view, hiss is simply explained by the accumulation of many whistlers trapped in the plasmasphere.

The purpose of this letter is to present the initial results from an investigation of hiss, using multi-component wave measurements by the High Frequency Waveform Receiver (HFWR) on the Polar satellite [Gurnett et al., 1995]. The theory of Thorne et al. [1979] predicts that, near the equator, waves propagating both northwards and southwards, more or less parallel and anti-parallel to $\boldsymbol{B}_{0}$ respectively, should be present together. A composite wave field like this cannot be regarded, even approximately, as being that of a single plane wave. Therefore we have studied the data by means of wave distribution function (WDF) analysis [Storey and Lefeuvre, 1979], which is able to distinguish between waves going in different directions.

\section{Data analysis}

We use data acquired in the high-rate telemetry mode of the Polar HFWR instrument, with a sampling frequency of $71.4 \mathrm{kHz}$. They are full vector measurements of both the electric and magnetic wave fields, made in snapshots of $0.445 \mathrm{~s}$ separated by gaps of $8.755 \mathrm{~s}$ [Gurnett et al., 1995]. In preparation for the analysis, the six waveforms in each snapshot are processed as follows: firstly they are "de-spun" by transforming them to a reference frame where one axis is the satellite spin axis, while the other two are fixed with respect to the Sun-Earth line; then a Fast Fourier Transform (FFT) is done on each of them; and lastly the transformed data are expressed in physical units, taking into account the known transfer functions of the instrument.

The data are searched for the presence of intense plasmaspheric hiss near the equator. We exclude all passes on which the electric antennas were oscillating, as they often did in the plasmasphere [Kolesnikova and Beghin, 2000]. Some interesting passes are illustrated in Figures 1 and 3. The quantity shown on a gray scale is the sum of the short-term power spectra of the three magnetic-field components. Our choices of the times and frequencies at which to make the WDF analyses are marked on the figures by the small white rectangles labelled A, B, etc. 
The magnetic-field data from all three of the search coils, together with the electric-field data from only the two long antennas, are used in the analyses. The input data for each analysis come from the set of FFTs for the snapshots in the chosen time interval (typically 30-50 s); they are the components of the FFTs of these five electromagnetic-field components in a narrow band centered on the chosen frequency. The choice of bandwidth, typically $50-110 \mathrm{~Hz}$, is a compromise between the needs for high resolution in frequency and for low statistical fluctuations; the integration period is limited to the $0.445 \mathrm{~s}$ duration of a snapshot. The five FFT data sets are then used to estimate the elements of the $5 \times 5$ spectral matrix of the five field components, and these 25 estimates are the actual input data for the WDF analysis. In this final step, the unknown WDF is estimated by fitting a multi-parameter model to these data. The model portrays the shape of the WDF at the chosen frequency, versus the wave-normal direction. Our method of analysis, titled "Model of Discrete Regions", is described in Appendix 3 of Santolik and Parrot [2000].

Usually a WDF is displayed as a pair of polar diagrams, one for each hemisphere of possible wave-normal directions. We use the reference frame with the $\mathrm{z}$-axis parallel to $\boldsymbol{B}_{\mathbf{0}}$, while the $\mathrm{x}$-axis lies in the magnetic meridian plane and is directed away from the Earth. Some examples are given in Figures 1 and 3. In each pair, the diagram on the left concerns waves propagating towards geographic North, the one on the right waves propagating towards geographic South. The polar angle $\theta$ is the angle between the wave normal and $B_{0}$; the azimuthal angle $\phi$ has its origin at the $x$-axis.

\section{Results}

Figure 1 shows a magnetic spectrogram of plasmaspheric hiss recorded in the evening sector during a southbound pass

through the equator on May 2, 1997. Notice that the hiss stops suddenly when the satellite reaches the equator. The electron density derived from the frequency of upper-hybrid emissions (not shown) also drops abruptly at this time, even though the satellite is inside the plasmasphere and moving towards the Earth. The most probable cause is a fairly rare phenomenon known as a plasmaspheric density cavity, seen previously in the data from CRRES [Carpenter et al., 2000].

WDF analyses have been performed at the two points marked on the spectrogram. The results, on the top of Figure 1, show that the wave energy is mainly concentrated near the center of each polar diagram. This means that two sets of waves, with their normals more or less parallel to $\boldsymbol{B}_{0}$ in one set and antiparallel in the other, are present simultaneously in both cases. Such waves could be amplified by the electron gyroresonance instability, as was suggested by Kennel and Petschek [1966]. If this were the case, we would expect the waves coming out of an amplifying region to be stronger than the waves going into it. Whenever the satellite passed through such a region, we would see a reversal in the predominant direction of flow of the wave energy. This is exactly what we see when we compare these two WDFs: at the point $A$ the north-going waves are slightly stronger than the south-going ones, while at $B$, south of $A$, the opposite is true (see Figure 2). Our results are consistent with an amplification of about $1.3 \mathrm{~dB}$ in a region centered $1.8^{\circ}$ north of the magnetic equator; the WDF estimates for other points support this interpretation.

Another spectrogram of plasmaspheric hiss is shown in Figure 3. The data were recorded in the morning sector on November 24,1996 , and the equator was crossed at roughly $L=3.6$. A strong emission of equatorial electromagnetic waves [Gurnett, 1976] was observed around $100 \mathrm{~Hz}$, but our concern was with the continuous hiss emission observed from 0623 UT $(L=5.8)$ until the end of the data record after 0733 UT $(L=3.3)$. The start
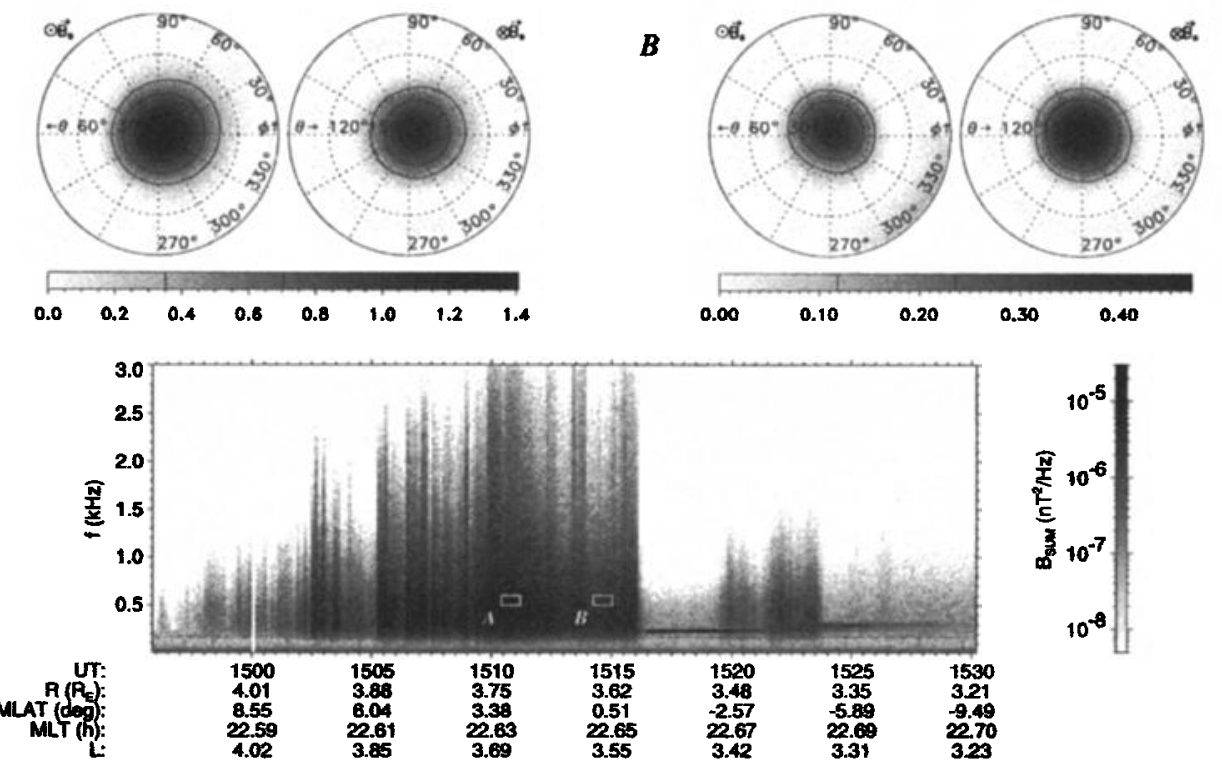

Figure 1. Data taken on May 2, 1997. (bottom) Spectrogram of the magnetic components of the wave field in the band 0-3 kHz; the gray scale is on the right. Universal time (UT), radial geocentric distance (R) in Earth radii, the magnetic latitude (MLAT) in degrees, the magnetic local time (MLT) in hours, and Mcllwain's parameter $(\mathrm{L})$ are below the spectrogram. (top) Estimated WDFs for the time-frequency intervals marked on the spectrogram by small white rectangles. The gray scale below each pair of plots gives the WDF values, in units of $10^{-18} \mathrm{~J} \mathrm{~m}^{-3} \mathrm{~Hz}^{-1} \mathrm{sr}^{-1}$. 
$\boldsymbol{A}$

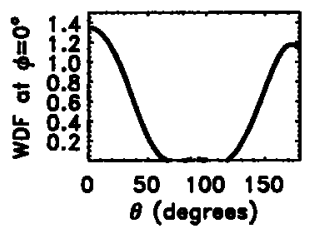

$\boldsymbol{B}$

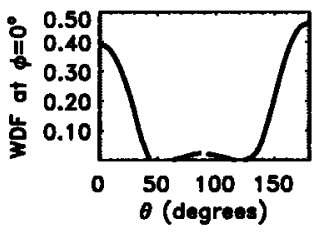

Figure 2. The values of the two WDFs of Figure 1 plotted as functions of $\theta$ with the azimuth fixed at $\phi=0^{\circ}$.

of the hiss activity corresponds to a rapid increase of the plasma density, and the widening of the frequency band after $0700 \mathrm{UT}$ also accompanies a rising density (not shown). The condition of the plasmasphere is consistent with the relatively long quiet period that preceded these observations: in the previous 24 hours the $\mathrm{K}_{\mathrm{p}}$ index did not exceed $2^{-}$, and was about $1^{-}$on the average. Figure 3 also shows a sequence of four WDFs, computed for the four points marked in the spectrogram. As before, we see a general tendency for the wave energy to be concentrated around the directions parallel and anti-parallel to the Earth's magnetic field, but in this case we also find some energy in directions much inclined to the field. These waves propagate close to the Gendrin angle [Gendrin, 1960], here about $85^{\circ}$, at an azimuth directed towards higher L-shells; they appear at the same azimuth in nearly all of the WDFs that we have estimated at other points in the time-frequency plane. They do not carry the major part of the wave energy, however. The main feature to notice in this figure is the clear-cut reversal in the predominant direction of energy flow that we see on comparing the WDFs for points A and B with those for points $C$ and $D$. It is consistent with an amplification of about $3 \mathrm{~dB}$ in a region centered roughly $8.5^{\circ}$ north of the geomagnetic equator. Similar results have been obtained from analyses over different frequency ranges, both higher and lower than the ones shown.

\section{Discussion}

Our analysis shows that, in the equatorial plasmasphere, hiss waves often propagate simultaneously around at least two principal directions, parallel and anti-parallel to the Earth's magnetic field. This result indicates that the waves may be amplified by the electron gyroresonance instability, as suggested by Kennel and Petschek [1966] and by Thorne et al. [1973, 1979]. Some of their energy, however, is found at wave-normal directions highly inclined to the Earth's magnetic field, near the Gendrin angle; recall that at this angle the energy again propagates along the Earth's magnetic field [Gendrin, 1960]. These oblique waves are like those observed by Storey et al. [1991] in the ISEE-1 data. In contrast, the present results show only a few of the waves propagating obliquely. This difference may be caused by the presence of the plasmapause in our cases, and by its absence in the cases that Storey et al. [1991] selected for this reason; Thorne et al. [1979] and Abel and Thorne [1998] have argued that reflection of the waves from the plasmapause is vital for the generation of hiss by the electron gyroresonance instability. Hence we conclude that, on some occasions, the hiss may be

$B$

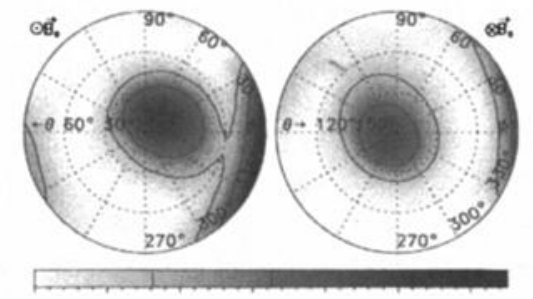

$\begin{array}{lllllll}0.000 & 0.005 & 0.010 & 0.015 & 0.020 & 0.025 & 0.030\end{array}$

D

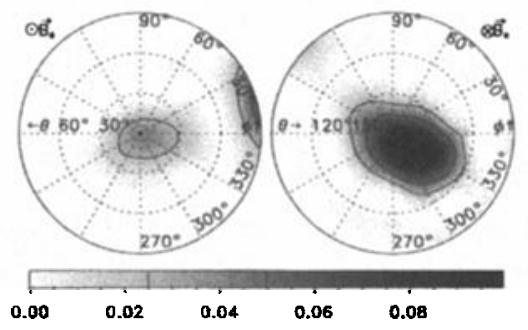

$\begin{array}{lllllll}0.000 & 0.010 & 0.020 & 0.030 & 0.040 & 0.050 & 0.060\end{array}$

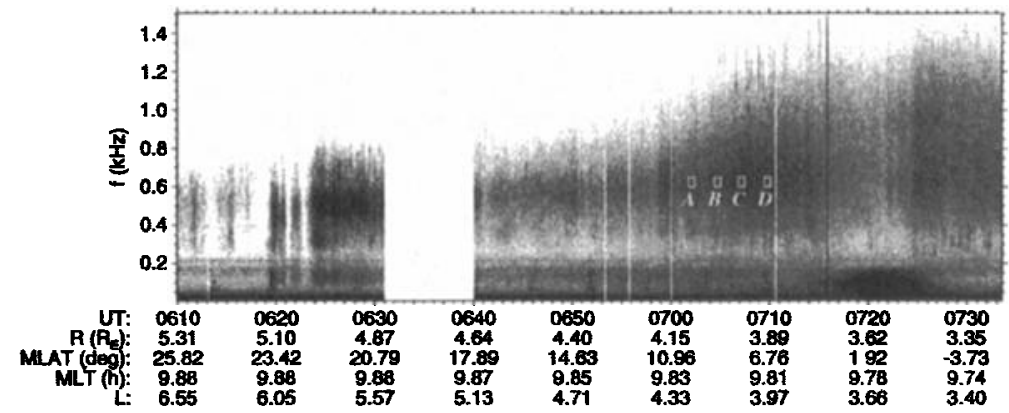

Figure 3. Data taken on November 24, 1996, and displayed in the same way as in Figure 1, except that the upper limit of the frequency band is now $1.5 \mathrm{kHz}$. 
generated by a different mechanism, but for our cases we cannot rule out the possibility that all of the waves originated with their normals close to $\boldsymbol{B}_{\mathbf{0}}$, and subsequently a small part of the energy escaped to the Gendrin angle either by propagation or by scattering from plasma density irregularities.

In the cases for May 2, 1997, and November 24, 1996, discussed above, the region of wave amplification may be located near the equator, at the magnetic latitudes $+1.8^{\circ}$ and $+8.5^{\circ}$ respectively. Theory predicts that the amplification should peak at the "minimum-B equator", the surface where the magnetic field strength has a minimum with respect to distance along any field line. Using the IGRF model of the Earth's field together with the T89c model for the contributions from external sources [Tsyganenko, 1989], we find that Polar crossed the minimum-B equator at the magnetic latitudes $-1.5^{\circ}$ and $+0.6^{\circ}$ respectively in the present cases. Thus our regions of apparent amplification are not centered on the minimum-B equator. The explanation may be that the condition for maximum wave amplification involves both the properties of the wave and those of the medium. The theory assumes that the medium is symmetrical with respect to the minimum-B surface. This is approximately true for the magnetic field and for the energetic electrons, but it is not necessarily true for the thermal plasma. If the distribution of electron density is different in the two hemispheres the region of amplification could be displaced as our data suggest.

We are not sure of our identification of the amplification regions, because the trajectory of the satellite is not parallel to the magnetic field. In both of the cases presented above, Polar is moving inward to lower L-shells as well as southward in magnetic latitude; the angle between the trajectory and $\boldsymbol{B}_{\mathbf{0}}$ is about $60^{\circ}$. Changes in the total intensity of the hiss, observed during both sequences of estimated WDFs, may well be due to this cross-L motion. Indeed, around 0651 on November 24 , 1996, we observe another reversal of the direction of the net wave-energy flux, further away from the minimum- $B$ equator than the two reversals discussed above. Moreover it has the opposite sign, corresponding to apparent absorption rather than amplification, and for this reason we regard it as an effect of the cross-L motion. That is to say, the satellite moves from an L-shell where the net energy flux has one direction to another where it has the opposite direction, observing an apparent reversal in the net flux, although, had it been moving solely in latitude on either of these L-shells, no reversal would have been observed. Conceivably all of the reversals can be explained in this way, as being due to motion across $\mathrm{L}$ instead of motion in latitude. Though with data from just two passes we cannot resolve this issue, it should be possible to do so statistically with data from many passes. If amplification is occurring in the observed range of $L$, then the reversals corresponding to apparent amplification should be more common than those corresponding to apparent absorption, and they should be clustered near the magnetic equator. If these predictions are confirmed, the next step should be to compare the observed amplification factors with the values given by the theory of the electron gyroresonance instability, using the energetic-electron distribution functions from some other instruments on Polar. These tasks are in our plans for future work.
Acknowledgments. We warmly thank J. Dowell who prepared the HWFR data for analysis. O. Santolík acknowledges the support of the International Program of Scientific Cooperation (PICS) 469, and of grants 205/98/0691 and 205/99/1712 from the Czech Grant Agency. D. Gurnett and J. Pickett were supported by the NASA Goddard Space Flight Center under Grant No. NAG5-7943.

\section{References}

Abel, B., and R. M. Thorne, Electron scattering loss in Earth's inner magnetosphere: 2. Sensitivity to model parameters, J. Geophys. Res., 103, 2,397-2,407, 1998.

Carpenter D. L., R. R. Anderson, W. Calvert, and M. B. Moldwin, CRRES observations of density cavities inside the plasmasphere, J. Geophys. Res., 105, 23,323-23,338, 2000.

Draganov, A. B., U. S. Inan, V. S. Sonwalkar, and T. F. Bell, Magnetospherically reflected whistlers as a source of plasmaspheric hiss, Geophys. Res. Lett., 19, 233-236, 1992.

Gendrin, R., Le guidage des whistlers par le champ magnétique, Planet. Space Sci., 5, 274-282, 1960.

Gurnett, D. A., Plasma wave interactions with energetic ions near the magnetic equator, J. Geophys. Res., 81, 2,765-2,770, 1976.

Gumett, D. A., A. M. Persoon, R. F. Randall, D. L. Odem, S. L. Remington, T. F. Averkamp, M. M. DeBower, G. B. Hospodarsky, R. L. Huff, D. L. Kirchner, M. A. Mitchell, B. T. Pham, J. R. Phillips, W. J. Schintler, P. Sheyko, and D. Tomash, The Polar Plasma Wave Instrument, Space Sci. Rev., 71, 597-622, 1995.

Kennel, C. F., and H. E. Petschek, Limit on stably trapped particle fluxes, J. Geophys. Res., 71, 1-28, 1966.

Kolesnikova, E., and C. Beghin, The instability problem of the electric field antennas on the POLAR spacecraft, Radio Sci., in print, 2000.

Santolík, O., and M. Parrot, Application of wave distribution function methods to an ELF hiss event at high latitudes, J. Geophys. Res., 105, $18,885-18,894,2000$.

Solomon, J., N. Cornilleau-Wehrlin, A. Korth, and G. Kremser, An experimental study of ELF/VLF hiss generation in the Earth's magnetosphere, J. Geophys. Res., 93, 1,839-1,847, 1988.

Storey, L. R. O., and F. Lefeuvre, The analysis of 6-component measurements of a random electromagnetic wave field in a magnetoplasma, 1, The direct problem, Geophys. J. R. Astron. Soc., 56, 255-270, 1979.

Storey, L. R. O., F. Lefeuvre, M. Parrot, L. Cairo, and R. R. Anderson, Initial survey of the wave distribution functions for plasmaspheric hiss observed by ISEE 1, J. Geophys. Res., 96, 19,469-19,489, 1991.

Thorne, R. M., E. J. Smith, R. K. Burton, and R. E. Holzer, Plasmaspheric hiss, J. Geophys. Res., 78, 1,581-1,596, 1973.

Thorne, R. M., S. R. Church, and D. J. Gorney, On the origin of plasmaspheric hiss: the importance of wave propagation and the plasmapause, J. Geophys. Res., 84, 5,241-5,247, 1979.

Tsyganenko, N. A., A magnetospheric magnetic field model with a warped tail current sheet, Planet. Space Sci., 37, 5-20, 1989.

D. A. Gurnett, J. S. Pickett, and O. Santolík, Department of Physics and Astronomy, University of Iowa, Iowa City, IA 52242-1479, U.S.A. (e-mail: gurnett@space.physics.uiowa.edu; jsp@space.physics. uiowa.edu; ondrej.santolik@mff.cuni.cz)

M. Parrot, Laboratoire de Physique et Chimie de l'Environnement, CNRS, 3A, Avenue de la Recherche Scientifique, F-45071 Orléans cedex 02, France. (e-mail: mparrot@cnrs-orleans.fr)

L. R. O. Storey, Quartier Luchène, Route du Luberon, F-84160 Cucuron, France. (e-mail: llewelyn.storey@physics.org)

(Received August 22, 2000; accepted November 29, 2000.) 